\title{
Whose risk is it anyway?
}

\section{David A Waller}

Powell et al ${ }^{1}$ have proposed the importance of 90-day mortality after lung cancer surgery, and have generated a predictive score using predominantly objective information. There are obvious advantages over the frequently quoted Thoracoscore ${ }^{2}$ which contains more subjective assessments of patient performance, and is based on data from a wide range of thoracic procedures including those for benign disease.

Their use of 90-day mortality as the outcome measure has merit, but its implications need further consideration. This measure may not reflect the standard of the operation. A lot can happen in that time: the risk of mortality in the first 3 months after surgery may be related to the side effects (direct or indirect) of adjuvant chemotherapy, or from comorbidity, that is, infective exacerbations of chronic obstructive pulmonary disease or even the natural history of the disease. The surgeon can only really influence the inhospital treatment; after discharge, the quality of primary care or medical care received from local referring physicians may also be important.

One wonders whether 90-day mortality was arbitrarily chosen for statistical reasons, and it is noted that no surgeon was involved as a coauthor of this paper. The parameter favoured for surgical performance would be inhospital mortality giving the patient an estimate of the chance of going home which must be their immediate priority.

When we report the apparent risk of an operation to remove a bronchogenic carcinoma the value is viewed by many parties involved in the interaction between patient and surgeon. This value means different things to different parties and begs the question: 'whose risk is it anyway?'

\section{THE PATIENT'S RISK?}

The risk of the operation is, of course, a personal matter for each patient which suggests that the use of any fixed cut-offs ignores this variability and would be denying surgery to some patients for whom it is the optimal treatment. Dowie used a decision-analytical approach to capture patient values taking account of the risk of operative death along with the potential for

Correspondence to Mr David A Waller, Department of Thoracic Surgery, Glenfield Hospital, Leicester LE3 9QP, UK; David.waller@uhl-tr.nhs.uk cure both by surgery and radiotherapy. ${ }^{3}$ This suggested that patients may well have a threshold probability of surgical mortality as high as $40 \%$ or in other words as we increase the chance of surgical mortality step by step (other things remaining the same), surgery remains the optimal choice until it reaches that figure. Since Dowie's publication, there have been significant developments in alternative radical therapies to surgery which may reduce this threshold. Stereotactic radiotherapy may now offer comparable outcome with reduced risk. In the Dutch experience, ${ }^{4}$ its introduction resulted in increased radiotherapy usage from $31 \%$ to $38 \%$ with populationbased increases in survival of elderly stage I lung cancer patients. Somewhat unexpectedly, surgical usage remained constant with significant improvements in survival observed in both the radiotherapy and surgery subgroups. Perhaps most importantly, there was a decline in the number of untreated patients.

For many patients, the risk of postoperative dyspnoea may be as important as mortality; immediate gain given priority over long-term benefit. Quality of life is detrimentally affected for all the 90-day postoperative period. ${ }^{5}$ This has been recognised in the British Thoracic Society guidelines for fitness for radical treatment of lung cancer. ${ }^{6}$ However, long-term dysfunction is rare. ${ }^{7}$

The doctor-patient interaction and communication skills are also an important determinant of risk perception. The way the risk is explained may be as important as the actual figures. 'The operation is $95 \%$ safe' sounds a lot more promising than 'you have a 1 in 20 chance of dying'. Try it for yourself.

So while the patient is, of course, the most important arbiter of operative risk, his perception may be different from the surgeon/physician and it would be naïve to suggest that it could ever be the sole dictator of practice. ${ }^{3}$

\section{THE REFERRING PHYSICIAN'S RISK}

The referring respiratory physician often undertakes the 'gatekeeper'role in the lung cancer pathway. They often chair the lung cancer multidisciplinary team (MDT) meetings, and may adopt the responsibility to decide whether or not patients with operable lung cancer should be offered surgery. Risk models are used to inform decision making of what acceptable surgical mortality should be. Unfortunately, they may be used to'protect' the patient from the overenthusiastic. This is why the presence of a surgeon's presence at the MDT has been shown to be essential in increasing the resection rate. ${ }^{8}$ The physician's role should be to gather the information to facilitate the calculation of a risk score which can then form the basis of MDT discussion.

\section{THE ANAESTHETIST'S RISK}

Surprisingly, the MDT discussion rarely involves the thoracic anaesthetist who is ultimately responsible for the operative risk of failing to regain spontaneous ventilation and subsequent intensive care. For many thoracic surgeons they are the final arbiter of operative risk and may be able to advise via preassessment clinics appropriate preparation to reduce the risk. Recent interest in enhanced recovery programmes for lung surgery, including preoperative rehabilitation ${ }^{9}$ and nutritional support, is likely to be beneficial.

\section{THE SURGEON'S RISK?}

Inevitably, however, the buck stops with the surgeon. He or she is faced with the dilemma between wishing to offer surgery for as many otherwise resectable tumours as possible against the consequences of resultant operative mortality. There is now compelling evidence that increasing the lung cancer resection rate may increase overall survival. Riaz et $a l^{10}$ have shown in the UK that a high frequency of resection was strongly inversely associated with overall mortality, and only moderately associated with mortality among the resected patients: 5420 deaths could be delayed overall for about 146 more deaths among the resected patients. Encouragingly, there is evidence of a significant increase in the UK resection rate ${ }^{11}$ related to an increase in surgery in higherrisk elderly females, the appointment of specialist thoracic (as opposed to cardiothoracic) surgeons, ${ }^{8}$ and an increase in the application of specialised techniques, that is, video assisted thoracic surgery lobectomy. ${ }^{12}$

Unfortunately, on the horizon, looms the spectre of the publication of surgeonspecific mortality rates promoted by the National Health Service Medical Director and already available on our surgical cousins in cardiac surgery. Inhospital mortality was chosen as a performance measure because ' it was understandable, easy to measure, could be validated, and included all patients who died in hospital (not just those within a certain time 
frame). Furthermore, it was used by all public reporting systems in the United States'.13

The measures of most use to the patient in making the operative decision in lung cancer, that is, 90-day mortality risk, as quoted by Powell et al, ${ }^{1}$ are not those chosen to performance manage surgeons, that is, 30 day or inhospital mortality. Indeed, it has been shown that reporting data on inhospital mortality after lobectomy for primary lung cancer is a poor tool for measuring a surgeon's performance. ${ }^{14}$. Lung cancer surgery is not comparable with adult cardiac surgery, where the intention is to improve the physiological status of the patient and where it is, therefore, appropriate to assess surgical performance by the immediate physiological risk of the operation. In lung cancer surgery, the long-term overall survival from resectable tumours is the most appropriate, albeit less easily assessable, outcome measure of surgical performance.

It has been recognised that publication of individuals' results remains controversial because of the potential, unintended, negative effects, and increasing recognition that individuals' results are strongly influenced by institutional influences and the ability to cater for casemix. ${ }^{13}$ The publication of outcomes by Lung MDT, as is now the case in the National Lung Cancer Audit, ${ }^{15}$ rather than by individual surgeon is to be encouraged. Similarly, the use of a population-specific risk model for UK lung cancer surgery can be used to support higher-risk surgery and discourage risk aversion.

The wider implications for the respective institution of higher-risk surgery should not be ignored. More detailed preoperative assessment will put pressure on the arbitrary 'target times' set for the lung cancer pathway and length of hospital stay. Unit management will be challenged by increased demand for critical care facilities, overall bed occupancy and possible detrimental effects on staff morale.

\section{CONCLUSION}

So how have times moved on since Treasure's Thorax editorial of 2002 'Whose lung is it anyway?'16 which previously considered the factors affecting the decision to operate? The major development in the last decade has been the improvement in data collection and the formation of the National Lung Cancer Audit. As Powell et al have shown, this extensive database now enables the patient to identify their particular team's record and also to calculate their more individualised risk. Questions still remain about how this data is to be used for service or manpower planning, or how it is to be presented to the patient. The purpose of its publication needs to be decided: to facilitate patient choice or show consistency of standards. Finally, spare a thought for the surgeon. To what extent do external influences affect his decision making ? While external review of his mortality figures remains the 'stick' for the lung surgeon, the 'carrot' is the encouragement to increase his resection rate.

\section{Competing interests None.}

Provenance and peer review Commissioned; internally peer reviewed.

To cite Waller DA. Thorax 2013;68:799-800.

Published Online First 25 May 2013

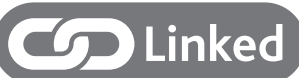

- http://dx.doi.org/10.1136/thoraxjnl-2012-203123

Thorax 2013;68:799-800

doi:10.1136/thoraxinl-2013-203536

\section{REFERENCES}

1 Powell H, Tata L, Baldwin DR, et al. Early mortality after surgical resection for Lung Cancer- an analysis of the English National Lung Cancer Audit. Thorax 2013:68:827-35.

2 Falcoz PE, Conti M, Brouchet L, et al. The Thoracic Surgery Scoring System (Thoracoscore): risk model for in-hospital death in 15,183 patients requiring thoracic surgery. I ThoracCardiovasc Surg 2007;133:325-32.

3 Dowie J, Wildman M. Choosing the surgical mortality threshold for high risk patients with stage la non-small cell lung cancer: insight from decision analysis. Thorax 2002;57:7-10.

4 Haasbeek CJ, Palma D, Visser O, et al. Early-stage lung cancer in elderly patients: a population-based study of changes in treatment patterns and survival in the Netherlands. Ann Oncol 2012:23:2743-7.

5 Balduyck B, Hendriks J, Lauwers P, et al. Quality of life evolution after lung cancer surgery: a prospective study in 100 patients. Lung Cancer 2007:56:423-31.

6 Lim E, Baldwin D, Beckles M, et al. Guidelines on the radical management of patients with lung cancer. Thorax 2010;65(Suppl 3):iii1-27.

7 McManus K. Concerns of poor quality of life should not deprive patients of the opportunity of curative surgery. Thorax 2003;58:189.

8 Lau KK, Rathinam S, Waller DA, et al. The effects of increased provision of thoracic surgical specialists on the variation in lung cancer resection rate in England. J ThoracOncol 2013;8:68-72.

9 Agostini P, Cieslik H, Rathinam S, et al. Pulmonary complications following thoracic surgery: are there any modifiable risk factors? Thorax 2010;65:815-18.

10 Riaz SP, Lüchtenborg M, Jack RH, et al. Variation in surgical resection for lung cancer in relation to survival: population-based study in England 20042006. Eur J Cancer 2012;48:54-60.

11 Riaz SP, Linklater KM, Page $\mathrm{R}$, et al. Recent trends in resection rates among non-small cell lung cancer patients in England. Thorax 2012;67:811-14.

12 Society for Cardiothoracic Surgery in Great Britain and Ireland. National Thoracic Surgery Activity and Outcomes Report 2011. http://www.scts.org

13 Keogh B, Spiegelhalter D, Bailey A, et al. The legacy of Bristol: public disclosure of individual surgeons' results. BMJ 2004;329:450-4.

14 Treasure T, Utley M, Bailey A. Assessment of whether in-hospital mortality for lobectomy is a useful standard for the quality of lung cancer surgery: retrospective study. BMJ 2003;327:73.

15 National Lung Cancer Audit Report 2012. http://www. haip.org.uk/national-lung-cancer-audit-report-2012

16 Treasure T. Whose lung is it anyway ? Thorax 2002:57:3-4. 